\title{
Predicting decadal trends and transient responses of radiocarbon storage and fluxes in a temperate forest soil
}

\author{
C. A. Sierra ${ }^{1}$, S. E. Trumbore ${ }^{1}$, E. A. Davidson ${ }^{2}$, S. D. Frey ${ }^{3}$, K. E. Savage ${ }^{2}$, and F. M. Hopkins ${ }^{1}$ \\ ${ }^{1}$ Max-Planck-Institute for Biogeochemistry, Hans-Knöll Str. 10, 07745 Jena, Germany \\ ${ }^{2}$ Woods Hole Research Center, Falmouth, MA 02540, USA \\ ${ }^{3}$ University of New Hampshire, Durham, NH 03824, USA
}

Correspondence to: C. A. Sierra (csierra@bgc-jena.mpg.de)

Received: 17 January 2012 - Published in Biogeosciences Discuss.: 28 February 2012

Revised: 28 June 2012 - Accepted: 29 June 2012 - Published: 8 August 2012

\begin{abstract}
Representing the response of soil carbon dynamics to global environmental change requires the incorporation of multiple tools in the development of predictive models. An important tool to construct and test models is the incorporation of bomb radiocarbon in soil organic matter during the past decades. In this manuscript, we combined radiocarbon data and a previously developed empirical model to explore decade-scale soil carbon dynamics in a temperate forest ecosystem at the Harvard Forest, Massachusetts, USA. We evaluated the contribution of different soil $\mathrm{C}$ fractions to both total soil $\mathrm{CO}_{2}$ efflux and microbially respired $\mathrm{C}$. We tested the performance of the model based on measurable soil organic matter fractions against a decade of radiocarbon measurements. The model was then challenged with radiocarbon measurements from a warming and $\mathrm{N}$ addition experiment to test multiple hypotheses about the different response of soil $\mathrm{C}$ fractions to the experimental manipulations. Our results showed that the empirical model satisfactorily predicts the trends of radiocarbon in litter, density fractions, and respired $\mathrm{CO}_{2}$ observed over a decade in the soils not subjected to manipulation. However, the model, modified with prescribed relationships for temperature and decomposition rates, predicted most but not all the observations from the field experiment where soil temperatures and nitrogen levels were increased, suggesting that a larger degree of complexity and mechanistic relations need to be added to the model to predict short-term responses and transient dynamics.
\end{abstract}

\section{Introduction}

Although quantifying the dynamics of soil carbon is a prerequisite for accurate representation of the response of this large reservoir to global change, few tools exist to construct belowground $\mathrm{C}$ budgets or to test existing models outside the range of conditions for which they have been parameterized. One of the major tools for understanding dynamics of soil $\mathrm{C}$ on decadal timescales is the rate and degree of incorporation of radiocarbon produced in the early 1960s by atmospheric thermonuclear weapons testing. Tracking of this "bomb" radiocarbon through physically and chemically fractionated soil organic matter provides information on which soil fractions are made from photosynthetic products fixed in the last decades, while the amount of radiocarbon measured in a given year allows estimation of rates of $\mathrm{C}$ turnover in the pool (Trumbore, 2009).

Comparison of $\Delta^{14} \mathrm{C}$ values of microbially respired $\mathrm{C}$ with possible $\mathrm{C}$ sources indicates which substrates contribute the most to heterotrophic respiration (Nowinski et al., 2010). The $\Delta^{14} \mathrm{C}$ value of soil respiration can be partitioned into contributions from fresh photosynthetic products and decomposition of older substrates. Together with observations of $\mathrm{C}$ stocks, such radiocarbon observations have been used to construct empirical belowground $\mathrm{C}$ budgets and assess carbon storage or release capacity for a few locations (e.g. Trumbore et al., 1995; Gaudinski et al., 2000). However, these budgets were originally constructed using assumptions of steady-state and required introduction of significant timelags in a long-lived fine root pool to close both $\mathrm{C}$ and radiocarbon budgets. These assumptions require testing that can 
only be accomplished by time-series measurements that track changes in radiocarbon in soil $\mathrm{C}$ fractions.

The assumption of steady-state is questionable in these belowground carbon models given the magnitude and extent of current environmental changes such as climate, $\mathrm{N}$ deposition, and land-use change. For modeling belowground $\mathrm{C}$ cycling, it is particularly important to understand the effects of changes in temperature and $\mathrm{N}$ deposition on the decomposition process (Schlesinger and Andrews, 2000). There is considerable evidence suggesting that increases in temperature generally increase mineralization rates of $\mathrm{C}$ (Bond-Lamberty and Thomson, 2010; Lloyd and Taylor, 1994; Davidson and Janssens, 2006). Similarly, the addition of $\mathrm{N}$ appears to decrease decomposition and respiration rates in temperate forest ecosystems (Janssens et al., 2010), promoting important changes in microbial dynamics (Treseder, 2008; Frey et al., 2004). Changes in temperature and nitrogen thus challenge the idea of steady-state in previously developed models. Harvard Forest, a deciduous temperate forest in the Northeastern United States, is one location where an empirical steady-state belowground $\mathrm{C}$ budget has been constructed (Gaudinski et al., 2000) based on radiocarbon measured in soil organic matter fractions and respired $\mathrm{CO}_{2}$. In addition, a number of experimental manipulations have been conducted at this forest, which provide demonstrated differences in short- and longterm responses of soil respiration to experimental manipulations. On the short term (months to a few years), soil warming $\left(+5^{\circ} \mathrm{C}\right)$ and $\mathrm{N}$ additions $\left(5-15 \mathrm{~g} \mathrm{~N} \mathrm{~m}^{-2} \mathrm{yr}^{-1}\right)$ produced significant increases in soil respiration rates (Melillo et al., 2002; Contosta et al., 2011; Bowden et al., 2004; Melillo et al., 2011). After several years and over the longer term (>10 $\mathrm{yr}$ of treatment), however, soil respiration rates in the temperature manipulation plots declined to levels close to those in the control plots (Melillo et al., 2002), and respiration and decomposition rates after $13 \mathrm{yr}$ of $\mathrm{N}$ addition were suppressed (Bowden et al., 2004). The initial increase followed by a decline in respiration rates in the soil warming plots was attributed to the exhaustion of a labile fast-cycling $\mathrm{C}$ fraction, which was assumed the only fraction to be temperature dependent (Melillo et al., 2002). The observed decrease in respiration and decomposition rates in the longterm $\mathrm{N}$ addition experiment was likely associated with suppression of the decomposer community and the production of lignin-degrading enzymes (Frey et al., 2004).

If differences between the short- (months) versus longterm (years) response in these manipulation experiments are associated with the responses of different $\mathrm{C}$ fractions in the soil organic matter pool, these responses could be distinguished by radiocarbon measurements. For example, a significant short-term release of young, labile soil $\mathrm{C}$ would be expected in response to warming or $\mathrm{N}$ addition experiments if this $\mathrm{C}$ fraction reacts strongly to the manipulations and is subsequently exhausted over time. On the other hand, a longterm response to temperature manipulation of larger, older C pools that are not quickly exhausted might also occur, but the effect on soil respiration might not be detectable if these pools contribute only a small fraction of the total soil $\mathrm{CO}_{2}$ efflux. In such cases, the $\Delta^{14} \mathrm{C}$ value of heterotrophically respired $\mathrm{C}$ may be more sensitive to a shift in substrate than the measure of $\mathrm{C}$ flux alone. Because the $\Delta^{14} \mathrm{C}$ value (age) differs among soil $\mathrm{C}$ components, it provides a tool for quantifying their relative contributions and how they differentially respond to environmental change. The age of microbially respired $\mathrm{C}$ provides information on the relative proportions of $\mathrm{C}$ fractions that contribute the most to soil and microbial respiration (Trumbore, 2009; Nowinski et al., 2010), and thus provides a sensitive indicator of how different substrates respond to manipulations.

The differential response of $\mathrm{C}$ fractions is difficult to study without the use of decomposition models. A model, as a synthesis tool, can give insights into the potential responses of the different pools to experimental treatments such as warming and $\mathrm{N}$ additions. In this sense, the model serves as a tool to explicitly generate hypotheses about the response of the system to external forcing (Canham et al., 2003). These quantitative hypotheses can then be used to compare to observations from field experiments and propose plausible explanations for the observed data.

The empirical model of soil $\mathrm{C}$ dynamics developed for Harvard Forest (Gaudinski et al., 2000) could help to provide plausible explanations for the observed response of different $C$ fractions to experimental manipulations if the steadystate assumption is relaxed. This model suggests that $\mathrm{C}$ is mostly stored in intermediate and relatively stable fractions, while respiration mostly originates from fast-cycling fractions (Fig. 1). Ecosystem manipulations such as warming and $\mathrm{N}$ additions may increase the decomposition and respiration rates from these different fractions (Rustad et al., 2001), but it is uncertain whether the response differs among them or whether one single fraction such as the labile fraction could be responsible for the main response to ecosystem manipulations.

In this study, we first tested the empirical model constructed by Gaudinski et al. (2000) by comparing predicted and observed long-term changes in the $\Delta^{14} \mathrm{C}$ values of soil respiration, microbial respiration, and soil organic matter density fractions in soils where no experimental manipulations have been conducted. We then explored the response of different soil organic matter fractions to warming and $\mathrm{N}$ additions at Harvard Forest and again compared the model predictions to measurements made in experimental plots subjected to temperature and $\mathrm{N}$ addition manipulations. By comparing model predictions with observations, we can ascertain if the hypothesized responses to warming and $\mathrm{N}$ addition are consistent with observations, and further, to what degree a differential response in decomposition rates of the different soil $\mathrm{C}$ fractions is detectable with the $\Delta^{14} \mathrm{C}$ value of the respired $\mathrm{CO}_{2}$. In terms of the specific response of these fractions, we pose the following alternative hypotheses: 


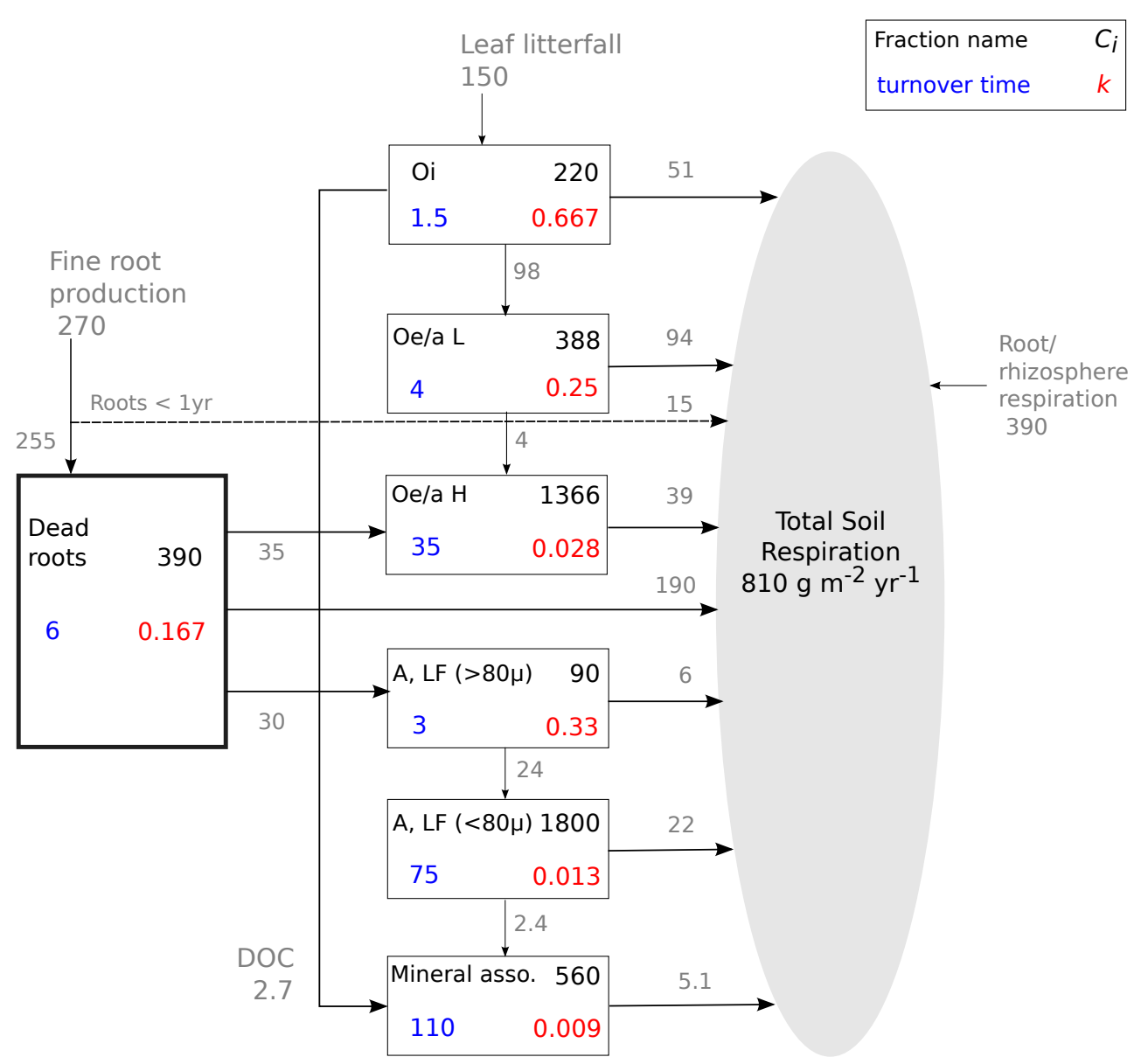

Fig. 1. Empirical model of soil carbon dynamics at Harvard Forest proposed by Gaudinski et al. (2000). The model consists of $6 \mathrm{C}$ fractions plus a dead fine root pool. Fluxes are represented in gray (units of $\mathrm{g} \mathrm{C} \mathrm{m}^{-2} \mathrm{yr}^{-1}$ ) while the amount of carbon at each fraction $\left(C_{i}\right)$ in black $\left(\mathrm{g} \mathrm{C} \mathrm{m}^{-2}\right)$. Turnover times $(\mathrm{yr})$ and decomposition rates $\left(\mathrm{yr}^{-1}\right)$ are represented in blue and red, respectively. "L" refers to the $>80 \mu \mathrm{m}$ fraction and " $\mathrm{H}$ " to $<80 \mu \mathrm{m}$ fractions in the organic layer. Note that the turnover time and decay rate of fine dead roots do not match the stocks and input rates. This mismatch is due to $\Delta^{14} \mathrm{C}$ values in fine roots far from the atmospheric value that suggests a turnover time of 6 years. This issue is well discussed in Gaudinski et al. (2000).

\section{Hypothesis 1:}

Decomposition rates for all $\mathrm{C}$ fractions respond in constant proportion to the $\mathrm{N}$ and temperature manipulations. In absolute terms, this means that the fastest cycling fraction has the largest increase in its decomposition rate. This hypothesis implies that relative measures of temperature sensitivity such as $\mathrm{Q}_{10}$ should be constant or similar for different $\mathrm{C}$ pools, consistent with some previous experiments (e.g. Fang et al., 2005; Reichstein et al., 2005).

\section{Hypothesis 2:}

Decomposition rates respond to experimental warming and $\mathrm{N}$ additions in a manner similar to the qualitative predictions of the Arrhenius equation. In relative terms, the more stable fractions are more sensitive to changes in temperature and $\mathrm{N}$, but the absolute change in decomposition rates is larger for the fast-cycling fractions (Sierra, 2012). A significant number of laboratory and field studies provide support for this hypothesis (Conant et al., 2011; Sierra, 2012).

\section{Hypothesis 3:}

Only decomposition of the labile or fast-cycling $\mathrm{C}$ fractions responds to experimental warming and $\mathrm{N}$ addition, whereas slower cycling fractions are controlled by processes that are not fundamentally temperature dependent and thus show no response. This is the case suggested by Melillo et al. (2002) as being responsible for the lack of a sustained long-term increase in soil respiration during the temperature manipulation experiment.

These three hypotheses are based on the assumption that warming and $\mathrm{N}$ additions would modify exclusively the decomposition rates of the different fractions, and a more explicit representation of them will be presented below. In 
addition, a number of previous studies report changes in pool sizes rather than changes in decomposition rates as a result of experimental manipulations. Therefore, we pose an additional hypothesis:

\section{Hypothesis 4:}

Only the size of the intermediate or decade-old fractions responds to warming and $\mathrm{N}$ additions without necessarily affecting the value of the decomposition rates. Although there is not a clear biological explanation for this hypothesis, it is a response that has been reported numerous times (MacDonald et al., 1995; Zoog et al., 1997; Waldrop and Firestone, 2004; Hopkins et al., 2012).

In all four cases, the effects of modifying decomposition rates and pool sizes on the $\Delta^{14} \mathrm{C}$ value of soil $\mathrm{CO}_{2}$ efflux and heterotrophic respiration are difficult to predict without the use of a model. In this case, we used Gaudinski et al. (2000) empirical model to formally define and test our hypotheses.

\section{Methods}

\subsection{Study site and experimental setup}

This study was performed at the Harvard Forest Long-Term Ecological Research (LTER) site, a temperate deciduous forest located in central Massachusetts, USA. This area has a history of 19th century agricultural land-use and a major hurricane disturbance in 1938. Current vegetation consists of mostly even-aged stands of mixed deciduous species and white pine (Fisher, 1921; Foster, 1988). Soils in the area were formed from glacial till, with bedrock of gneiss, schist, and granite. These soils have been classified as Typic Dystrochrepts and their texture designated as fine sandy loam (Borken et al., 2006).

Data on radiocarbon in atmospheric $\mathrm{CO}_{2}$, soil organic matter and soil $\mathrm{CO}_{2}$ efflux have been taken at different sites within Harvard Forest since 1996 (Gaudinski et al., 2000; Trumbore, 2000; Borken et al., 2006). In this manuscript, we compiled data from previous studies and other previously unpublished data for testing the performance of the empirical model. In addition, we analyzed samples from the Soil Warming $\times$ Nitrogen Addition Study (Contosta et al., 2011) using the same methods as for the long-term measurements to test the four hypotheses presented above. This experiment was started in August 2006 and consists of four experimental treatments: control, warmed, $\mathrm{N}$ addition, and the interaction warming $\times \mathrm{N}$, with six experimental replicates per treatment. Temperature in the warming treatment is continuously elevated $5^{\circ} \mathrm{C}$ above ambient, while in the $\mathrm{N}$ addition treatment, $\mathrm{N}$ is added at a rate of $5 \mathrm{~g} \mathrm{~m}^{-2} \mathrm{yr}^{-1}$. Additional details about the experimental setup are described in Contosta et al. (2011).
From each treatment, three plots were used to sample soil cores and measure radiocarbon of heterotrophically-respired $\mathrm{CO}_{2}$ at three different points in time (see description of radiocarbon methods below). The first set of measurements was made two months after the start of the experiment, on 3 October 2006. A second sampling was conducted on 23 September 2008, approximately two years after the start of the experiment. On 5 July 2010, four years after the start of the experiment, a third set of samples was taken.

In addition, samples of atmospheric $\mathrm{CO}_{2}$ and soil $\mathrm{CO}_{2}$ efflux from respiration chambers were taken at irregularly spaced intervals between 2006 and 2010 on a total of 13 sampling dates.

\subsubsection{Radiocarbon in soil $\mathrm{CO}_{2}$ efflux in situ}

The $\mathrm{CO}_{2}$ entering the atmosphere from soil integrates a number of processes, including $\mathrm{C}$ derived from plant root respiration and decomposition of organic matter. Samples for isotopic measurements of soil $\mathrm{CO}_{2}$ efflux were collected from chambers that enclosed an air headspace in contact with the soil surface in the absence of vegetation (Davidson et al., 1998; Savage and Davidson, 2001) using a closed dynamic chamber system to collect accumulated $\mathrm{CO}_{2}$ in stainless steel traps with a molecular sieve inside. Details about the method are presented in Gaudinski et al. (2000). Since 2007 this method has been modified in that we no longer scrub the chamber air free of initial $\mathrm{CO}_{2}$, but instead assume the chamber air initially had the concentration and isotopic signature of the atmosphere, and then we measure the $\mathrm{CO}_{2}$ mixing ratio after it accumulated in the chamber for a time that varied from 10 to $30 \mathrm{~min}$. The $\Delta^{14} \mathrm{C}$ value of the $\mathrm{CO}_{2}$ efflux was then calculated by mass balance.

For all measurements, the molecular sieve traps of $\mathrm{CO}_{2}$ headspace air were transported to the WM Keck Carbon Cycle Accelerator Mass Spectrometry facility at the University of California at Irvine, where the traps were heated to release trapped $\mathrm{CO}_{2}$. The $\mathrm{CO}_{2}$ was purified, reduced to graphite target, and measured for radiocarbon as discussed in Xu et al. (2007). Results are reported as average \pm standard deviation of three samples of cryogenically purified air samples.

\subsubsection{Microbially respired radiocarbon in vitro}

For radiocarbon measurements of microbially respired $\mathrm{CO}_{2}$ (heterotrophic respiration), soil samples were collected from the organic layer (Oi and Oe/a horizons) and the first $5 \mathrm{~cm}$ of the mineral A-horizon using soil cores of $5 \mathrm{~cm}$ diameter. Stones, large roots, and intact root networks were removed prior to incubation, and samples sat for several days prior to incubation to allow remaining roots to die, so as to minimize contributions from root respiration. The samples were then purged with $\mathrm{CO}_{2}$ free air and incubated in glass jars for a short period of time (one to two weeks) until enough $\mathrm{CO}_{2}$ had accumulated in the jar's headspace for isotopic analysis. 
The $\mathrm{CO}_{2}$ sampled from these jars was collected, purified, and analyzed at the AMS facility at UC Irvine as above.

\subsubsection{Radiocarbon in organic matter fractions}

For testing the original empirical model in un-manipulated soils, three soil pits were dug in 2007 at locations within 1$5 \mathrm{~m}$ of the three original soil pits sampled in 1996-1997 by J. Gaudinski (Gaudinski et al., 2000). Samples were taken from the O- $(0-8 \mathrm{~cm})$ and the A-horizon $(8-15 \mathrm{~cm})$. These samples were sieved $(<2 \mathrm{~mm})$ and large roots were removed. These pits are co-located with the soil respiration measurement collars, except for the years 2001-2003, when respiration samples were taken in the same soil type/drainage but about $0.5 \mathrm{~km}$ away.

Treatment of soil samples and isolation of fractions was the same as reported in Gaudinski et al. (2000). Briefly, organic horizon material was sieved to separate larger, recognizable organic matter $(>80 \mu \mathrm{m})$ from humified materials too small to be identified $(<80 \mu \mathrm{m})$. Mineral soils were fractionated by density using sodium polytungstate into low density $\left(<2.1 \mathrm{~g} \mathrm{~cm}^{-3}\right)$ and high density $\left(>2.1 \mathrm{~g} \mathrm{~cm}^{-3}\right.$, mineral-associated) $\mathrm{C}$ fractions. The low-density organic matter was further separated by sieving into components larger and smaller than $80 \mu \mathrm{m}$. The resulting fractions were dried, homogenized and ground, and an aliquot was combusted $\left(900^{\circ} \mathrm{C}\right)$ after sealing in an evacuated quartz tube with cupric oxide wire. The $\mathrm{CO}_{2}$ evolved during combustion was purified, reduced to graphite and measured by AMS as above. We do not report $C$ inventory data here. Spatial variation is large and, any changes in $\mathrm{C}$ inventory would not be detectable with only three soil pits; $\mathrm{C}$ inventories are assumed to have remained the same as those reported in Gaudinski et al. (2000). Data are reported as the average of the three replicates, with error bars representing the standard deviation.

Radiocarbon measurements are reported as ${ }^{14} \mathrm{C}$ values (Stuiver and Polach, 1977), the deviation of the ${ }^{14} \mathrm{C} /{ }^{12} \mathrm{C}$ ratio in the sample corrected to a common $\delta^{13} \mathrm{C}$ of $-25 \%$ ( $\mathrm{SN}$ ) from the ${ }^{14} \mathrm{C} /{ }^{12} \mathrm{C}$ value of oxalic acid decay-corrected to 1950 (ABS):

$\Delta{ }^{14} \mathrm{C}=1000 \times\left(\frac{\left(\frac{{ }^{14} \mathrm{C}}{{ }^{12} \mathrm{C}}\right)_{\mathrm{SN}}}{\left(\frac{{ }^{14} \mathrm{C}}{{ }^{12} \mathrm{C}}\right)_{\mathrm{ABS}}}\right)$.

\subsection{Empirical model}

Using measurements of radiocarbon in soil $\mathrm{CO}_{2}$ efflux and heterotrophic respiration as well as measurements of carbon stores and fluxes, Gaudinski et al. (2000) proposed an empirical model of carbon dynamics for the soils in the Prospect Hill track (Fig. 1). This model integrated the pool size and turnover times estimated from the data collected previously, so the carbon fractions in this model correspond to the measured fractions. The model was implemented numerically in the $\mathrm{R}$ environment for computing, and the code is provided in the supplementary material. In addition, all code and data used to produce the results from this analysis are provided in the supplementary material for reproducibility (Mesirov, 2010; Peng, 2011).

The model consists of 6 organic matter fractions with different turnover times and size (amount of carbon stored). In addition, dead fine root mass represents an additional pool in the model. The organic and the mineral layers are composed of three fractions each (Fig. 1), and are based on the measured fractions isolated in sample preparation. In the organic layer, fresh recognizable litter fragments form one fraction (Oi), and recognizable litter fragments $>80 \mu \mathrm{m}$ in size from the $\mathrm{Oe}+\mathrm{Oa}$ horizons form another fraction (Oe/a L), while humified material $<80 \mu \mathrm{m}$ in size from the $\mathrm{Oe}+\mathrm{Oa}$ horizon forms the third fraction (Oe/a $\mathrm{H})$. In the mineral layer, organic matter from the A-horizon is distinguished based on its density and particle size. The A, LF $(>80 \mu \mathrm{m})$ and the A, $L F(<80 \mu \mathrm{m})$ fractions represent the low-density organic matter with particles larger and smaller than $80 \mu \mathrm{m}$ in diameter, respectively. A third fraction comprises all the organic matter that is mineral associated (Fig. 1). Roots in this model have a mean residence time of $6 \mathrm{yr}$. This value is close to a more recent analysis that reports mean residence times for fine roots in the organic layer between 5 and $7 \mathrm{yr}$, and between 6 and $13 \mathrm{yr}$ in the first centimeters of the mineral layer (Gaudinski et al., 2010).

For modeling $\Delta^{14} \mathrm{C}$ values in soil organic matter and respiration pools, we made three simple assumptions: (1) the carbon content for each fraction reported in Fig. 1 was used as the initial values of the simulation; (2) simulations started in the year 1900 using the atmospheric record of ${ }^{14} \mathrm{C}$ values (Levin and Kromer, 2004) corrected by our own measurements of atmospheric $\Delta^{14} \mathrm{CO}_{2}$ during the study period and tree ring measurements for earlier periods (Gaudinski et al., 2009); (3) the inputs of organic matter from litter and roots were considered constant during the entire simulation period and were equal to those reported in Fig. 1.

The performance of the model was assessed in two different ways. (1) Model predictions were compared with radiocarbon measurements taken in 2007 of the different soil fractions described above, and (2) model predictions were compared with measurements of radiocarbon of total soil respiration.

In addition to assessing model performance, the hypotheses presented above were reproduced with the empirical model to compare predictions with the measurements from the experimental study.

To explore the effect of changes in decomposition rates and the size of the $\mathrm{C}$ fractions on $\Delta^{14} \mathrm{C}$ values and compare with observations from the experimental study, we performed simulations within the framework of the GLUE methodology (Beven and Binley, 1992; Beven, 2006). This methodology is widely used for model rejection and for exploring sensitivity of the model's parameters. A model run with a specific parameter set $\mathrm{M}(\Theta)$ is not rejected (is 


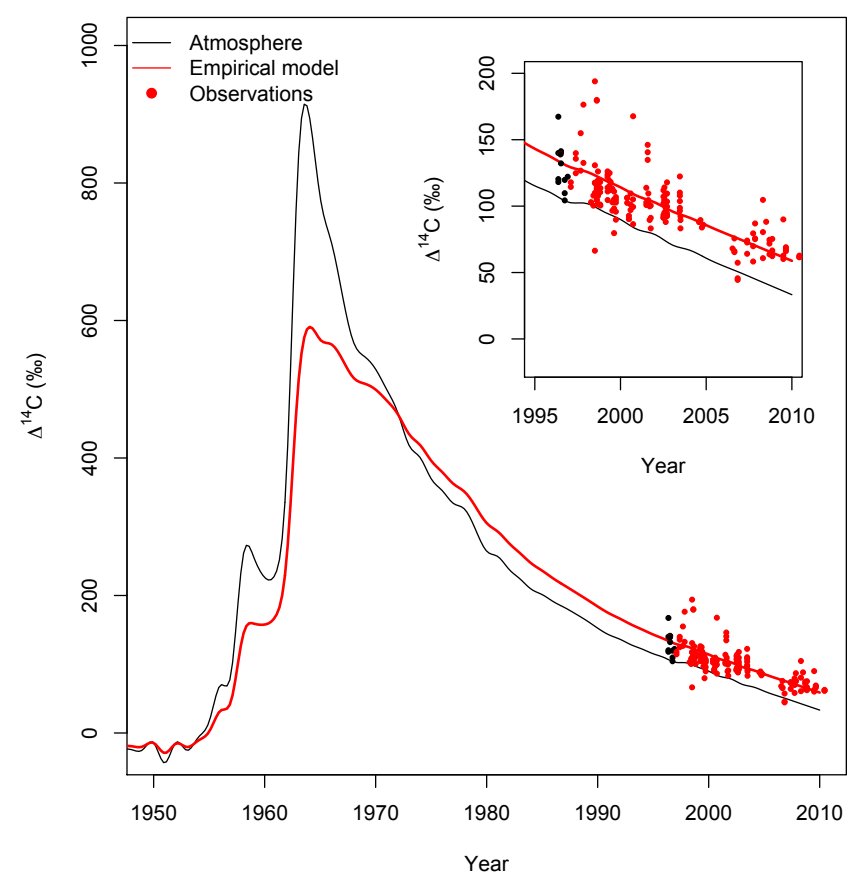

Fig. 2. Comparison of the performance of the empirical model proposed by Gaudinski et al. (2000) with measurements of $\Delta^{14} \mathrm{C}$ in soil $\mathrm{CO}_{2}$ efflux conducted in Harvard Forest between 1996 and 2010. Black points represent measurements used to develop the empirical model, and red points independent observations. The atmosphere record is $\sim 5 \%$ o below the background atmosphere published by Levin and Kromer (2004), and is based on data collected from tree ring $\Delta^{14} \mathrm{C}$ and atmospheric samples (Gaudinski et al., 2009).

"behavioral" in GLUE jargon) if it can provide reasonable predictions of the observed data $\mathrm{O}$. The criteria for rejecting a model are evaluated with a likelihood measure LM that quantifies the deviation of the model prediction from the observations. In our case, we defined the likelihood measure with a triangular distribution as in Wetterstedt and Ågren (2011):

$\operatorname{LM}(M(\Theta), O)=\left\{\begin{array}{l}\frac{M-O_{\text {min }}}{\mathrm{O}_{\text {mean }}-O_{\min }}, M \leq O_{\text {mean }} \\ \frac{O_{\text {max }}-M}{O_{\text {max }}-O_{\text {mean }}}, M>O_{\text {mean }}\end{array}\right\}$

The likelihood measure returns a value of 1 if the model output is equal to the average of the observations. It returns a value of 0 if the output is equal to the mean \pm standard deviation of the observations. Negative values represent nonbehavioral models, i.e., combinations of parameters in the model that produce output outside the $68 \%$ confidence interval of the observations. To obtain meaningful results, a large number of combinations of parameter values should be explored. In our case, we run 500 simulations with random draws from uniform distributions of selected parameters to evaluate the likelihood measure.

\section{Results}

\subsection{Observed changes in radiocarbon over the decade 1997-2007: soil $\mathrm{CO}_{2}$ efflux and heterotrophic respiration}

Radiocarbon in atmospheric $\mathrm{CO}_{2}$ decreased at a rate of 5$6 \%$ per year during the decade of observations at the Harvard Forest, based on tree ring analysis and local atmospheric air sampling (Gaudinski et al., 2010, Fig. 2). The radiocarbon in total soil respiration, while highly variable in space and time due to variations in soil moisture (Borken et al., 2006), roughly parallels the slope of the atmospheric radiocarbon, as would be expected given contributions from recent photosynthetic products by root respiration. It is consistently higher than the atmosphere in any given year, indicating the contribution of organic $\mathrm{C}$ fixed several years to decades previously (Fig. 2). Microbially respired $\mathrm{C}$ from litter and A-horizon soil sampled at several points in time was shown to be even higher in radiocarbon than total soil respiration, which suggests that the observed soil respiration is on average a mix of roughly equal proportions of recent photosynthetic products and decomposing organic matter (Gaudinski et al., 2000).

\subsection{Model performance}

The empirical model (Fig. 1) was able to predict the general trend of $\Delta^{14} \mathrm{C}$ in soil $\mathrm{CO}_{2}$ efflux over time (Fig. 2). Even though the model was parameterized using data sampled in 1996 only, it performs well at predicting radiocarbon measurements of ${ }^{14} \mathrm{CO}_{2}$ over the ensuing decade.

\subsection{Model performance in the period 1997-2007 - soil C fractions}

Compared to respired $\mathrm{C}$, the changes in $\Delta^{14} \mathrm{C}$ of the organic matter fractions over the $11 \mathrm{yr}$ of sampling were much smaller (Fig. 3). The largest change was in the Oi-horizon, which parallels the drop in atmospheric radiocarbon. The Oe/a layer and the low-density fraction of the A mineral horizon had higher ${ }^{14} \mathrm{C}$ signatures and decreased less between 1997 and 2007. The dense fraction A-horizon material had lower $\Delta^{14} \mathrm{C}$ values and either increased slightly or stayed the same from 1997 to 2007. The presence of $C$ with $\Delta{ }^{14} \mathrm{C}>0 \%$ indicates that some of the $\mathrm{C}$ in this fraction turns over fast enough to incorporate bomb radiocarbon fixed since 1963, while the increase from 1997-2007 can only occur for fractions with turnover times long enough that the "peak" from 1963 has not yet arrived; i.e. turnover times larger than $60 \mathrm{yr}$. Although only data for the A-horizon are shown here, we observed no significant changes in radiocarbon for deeper soil horizons (>15 cm depth) between 1997 and 2007. The A-horizon and organic layers together are responsible for more than $80 \%$ of soil respiration fluxes (Davidson et al., 2006; Gaudinski et al., 2000), so we have not included deeper layers in the analysis here. 


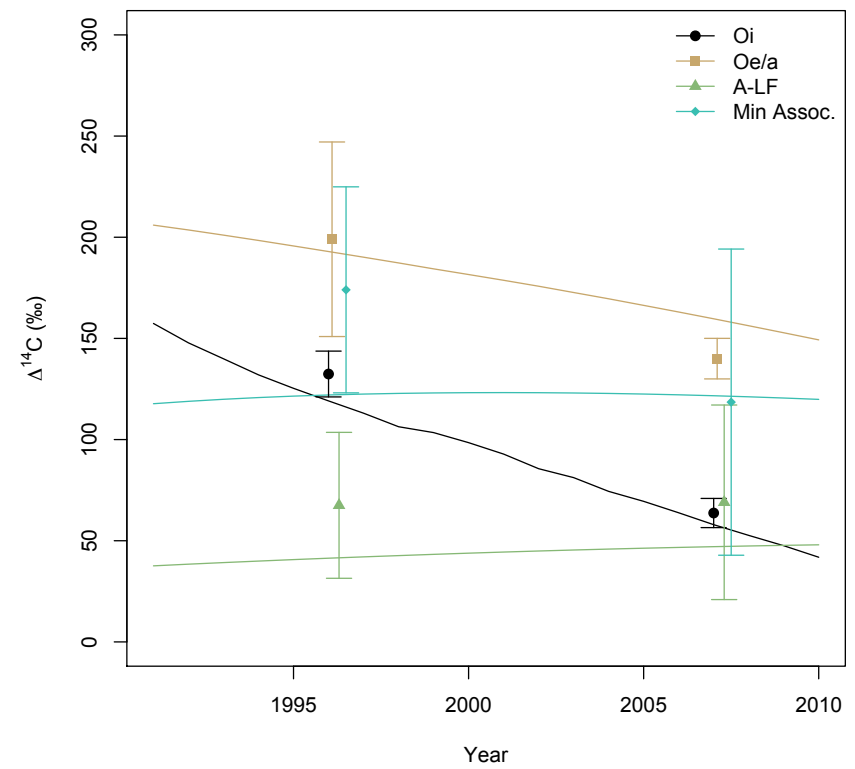

Fig. 3. Assessment of model performance comparing predictions with observations of $\Delta^{14} \mathrm{C}$ of soil $\mathrm{C}$ fractions. Points are measurements; lines are model results from Gaudinski et al. (2000). The $\mathrm{Oe} / \mathrm{a}$ fraction combines the Oe/a $\mathrm{L}$ and Oe/a $\mathrm{H}$ fractions of the original model. Similarly, A-LF $(<80 \mu \mathrm{m})$ and A-LF $(>80 \mu \mathrm{m})$ were combined in a single fraction.

The empirical model also performed well at predicting the radiocarbon content in bulk soil for the different $\mathrm{C}$ fractions (lines in Fig. 3). Although the spatial variation is very large, the general patterns and absolute radiocarbon contents of the different soil fractions agree with the model predictions.

\subsection{Radiocarbon in respired $\mathrm{CO}_{2}$ at the Soil Warming $x$ Nitrogen Addition Study}

Measurements of radiocarbon in the respired $\mathrm{CO}_{2}$ for each treatment level were consistently above the atmospheric values at each sampling date and showed a slight declining trend over time in parallel with the background atmospheric ${ }^{14} \mathrm{CO}_{2}$ (Fig. 4). These $\Delta^{14} \mathrm{C}$ values showed a large degree of variability, and therefore, an analysis of variance showed no significant differences among the different treatments for the different sampling dates $(p=0.24$ for interaction between treatment and sampling date, from $F=1.19$ with 35 degrees of freedom). In particular, large variability in the heated treatment was due to a single plot that had much higher $\Delta^{14} \mathrm{C}$ values than all others even before the treatment began. Over the several years of the experiment's duration, this effect diminished.

Heterotrophic respiration measured in laboratory incubations also showed a large degree of variability in $\Delta^{14} \mathrm{C}$ values, especially for the organic horizons (Fig. 5). For the mineral horizons though, there was evidence for a treatment effect at the two month and four year samplings.

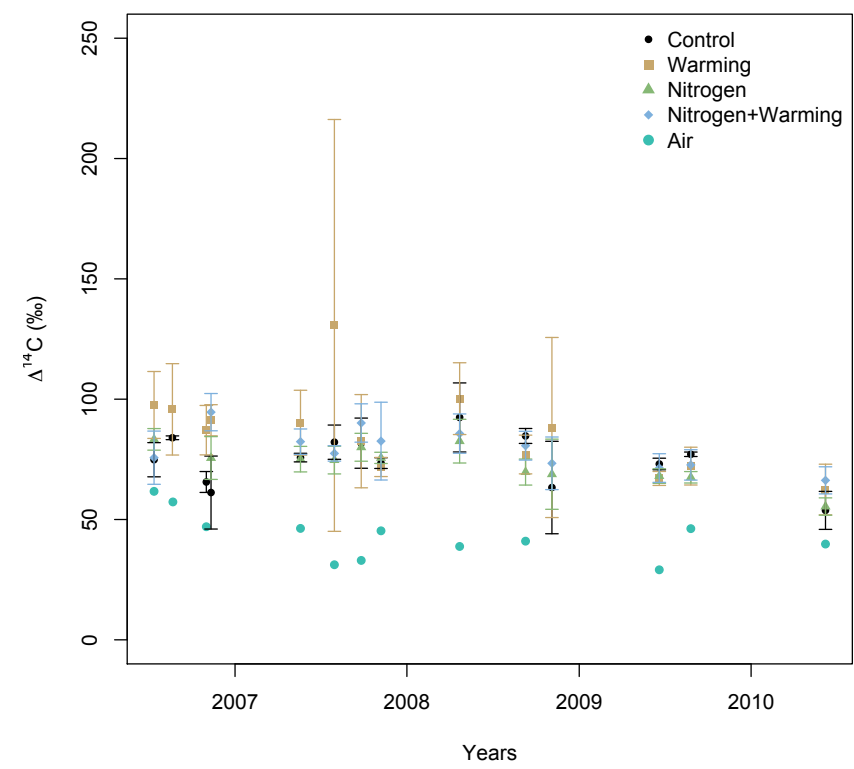

Fig. 4. Radiocarbon in respired $\mathrm{CO}_{2}$ measured in field traps at treatments and sampling dates between 2006 and 2010. Bars represent the standard deviation of the sample at each sampling date.

After the first two months, warming, $\mathrm{N}$ addition, and their interaction promoted a release of $\mathrm{C}$ from the mineral layer with significantly higher $\Delta^{14} \mathrm{C}$ values compared to the control treatment (Fig. 5b, $p<0.01$, from $F=0.24$ with 7 d.f. and Dunnett's correction for multiple comparisons). This treatment effect suggests that the experimental manipulations promoted the release of decade-old carbon in the mineral layer. However, this effect was not consistent for all sampling dates. Two years after the start of the experiment, there were no significant differences among the treatments (Fig. 5 d, $p=0.2, F=1.9$ with 8 d.f.). After $4 \mathrm{yr}$, there were differences again among the control and the manipulations, but in this case only for $\mathrm{N}$ addition and its interaction with warming (Fig. 5f, $p<0.1, F=3.4$ with 8 d.f.).

\subsection{Modeling runs}

\subsubsection{Evaluation of hypotheses 1, 2 and 3}

To develop testable hypotheses with the model of Fig. 1 proposed by Gaudinski et al. (2000), it is useful to plot the decomposition rate constants and the amount of carbon in each pool ranked by the value of the decomposition rate (Fig. 6). With this representation, it is easier to see that in these soils most of the $\mathrm{C}$ is stored in pools with low and intermediate decomposition rates. Hypotheses about the proportional increase in decomposition rates can now be based on the rates proposed by Gaudinski et al. (2000) (Fig. 7).

Measurements of soil $\mathrm{CO}_{2}$ efflux showed that the proportional increase due to the experimental manipulations are between 40 and $50 \%$ higher than in the control 
a
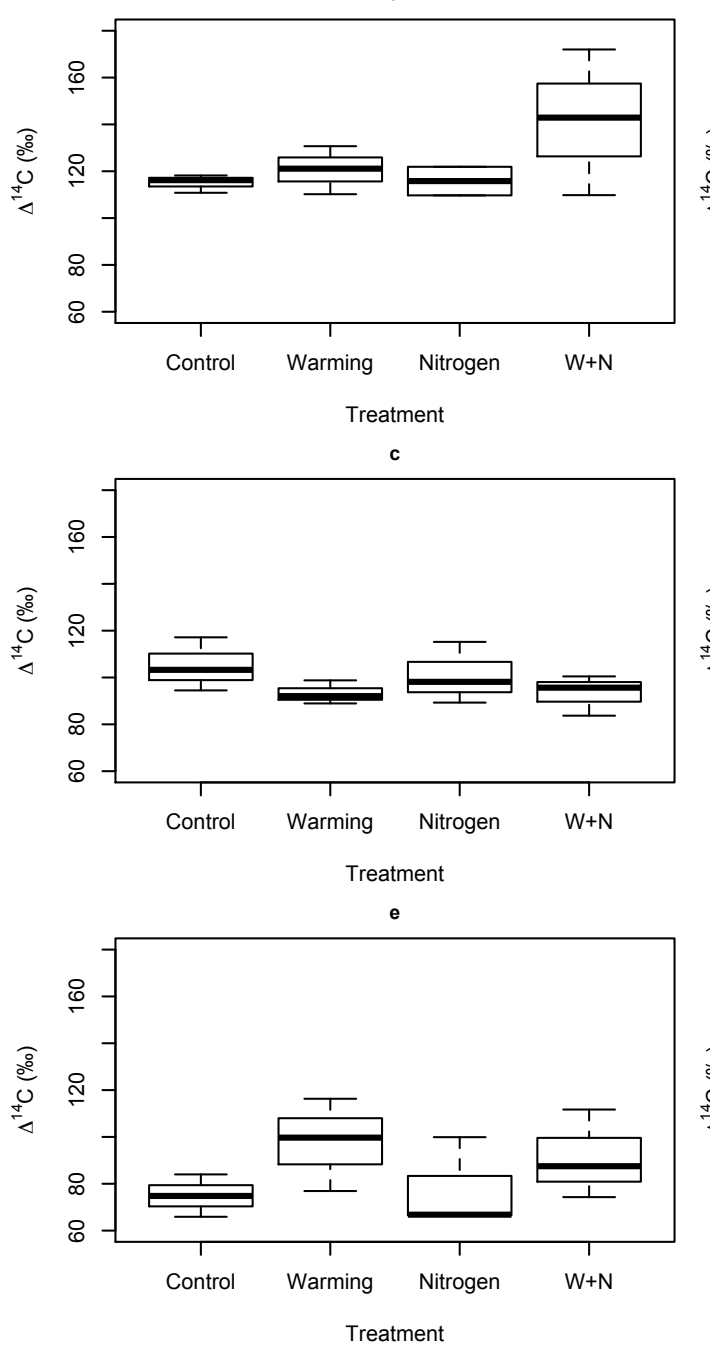

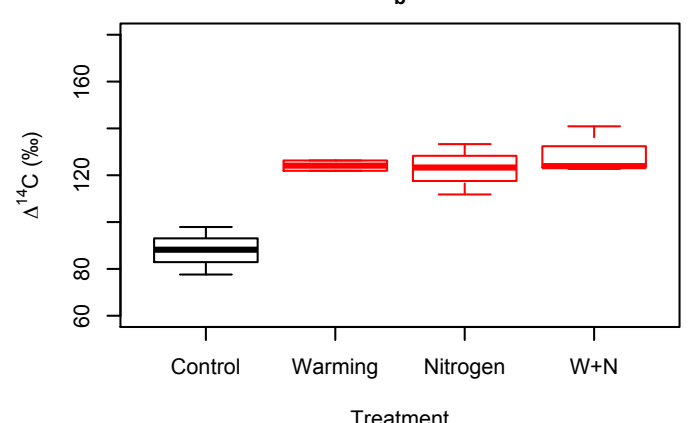

d

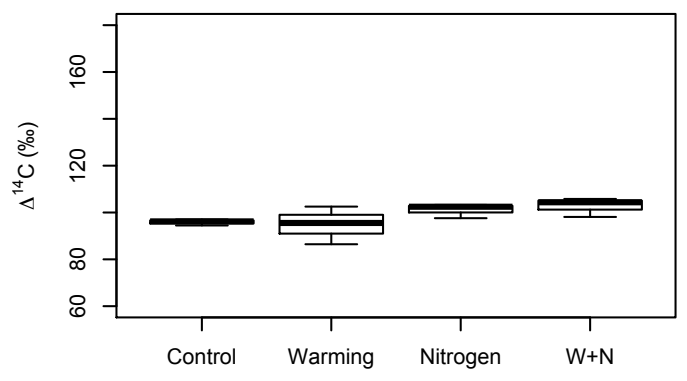

Treatment

f

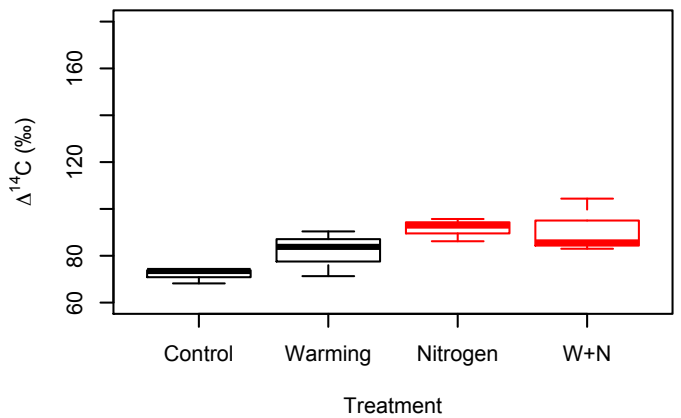

Fig. 5. Box plots of $\Delta^{14} \mathrm{C}$ values in laboratory incubations measured in the organic (left-hand side panels) and mineral layers (right-hand side panels) two months (a, b), two years (c, d), and four years (e, f) after the start of the experiment. Differences in color represent statistical differences with the control treatment with $\alpha=0.05$ and Dunnett's correction for multiple comparison.

(Contosta et al., 2011). With this information, it is possible to explicitly pose hypotheses for the potential increase in decomposition rates for the different carbon fractions (Fig. 7). In the first hypothesis (H1), all rates were increased by a factor of 1.5 , which was the proportional increase in respiration rates reported by Contosta et al. (2011). For the second hypothesis $(\mathrm{H} 2)$, the rates were increased by a higher proportion in the pools with lower decomposition rates than in the pools with higher decomposition rates, but on average the proportional increase for all the pools was still a factor of 1.5 (Fig. 7a). For the third hypothesis (H3), only the decomposition rates of the fast-cycling fractions in the mineral and organic layers were increased by a factor of 1.5 (Fig. 7).

All hypotheses predict larger changes in the absolute value of the decomposition rate for the fast-cycling fractions, with larger changes for $\mathrm{H} 1$ and $\mathrm{H} 3$. Although $\mathrm{H} 2$ predicts a larger proportional increase in the decomposition rates for the more stable fractions, in absolute values this increase is not very different than the increase predicted by $\mathrm{H} 1$ and $\mathrm{H} 3$ (Fig. 7b).

When the model was run with the increases in decomposition rates predicted by the three hypotheses, we found very small differences in the predictions of $\Delta^{14} C$ values in respired fluxes for fractions both in the organic and the mineral layers (Fig. 8). The difference in predictions is larger for the organic horizon, while the differences for the mineral layers are almost indistinguishable. This is caused by the low values of decomposition rates in the mineral layer, which increase very little in absolute amounts compared to the pools in the organic layer, which have higher decomposition rates and therefore larger absolute changes.

As shown before, the measurements of $\Delta^{14} \mathrm{C}$ present a large degree of variability, and for this reason it is not 

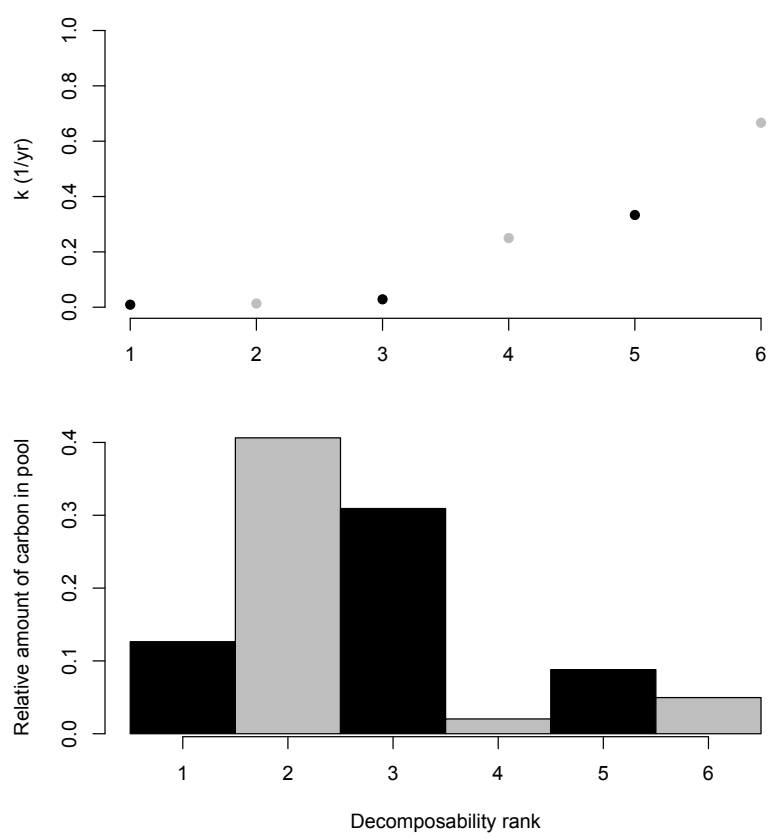

Fig. 6. Representation of the decomposition rate constants and pool sizes ranked by the value of the decomposition rate in the empirical model proposed by Gaudinski et al. (2000). Black colors represent pool sizes and decomposition rates for the mineral layer, and gray colors for the organic layer. Decomposability ranks match pool names in Fig. 1 as: 1: Mineral asso., 2: Oe/a, 3: A-LF ( $<80 \mu \mathrm{m}), 4$ : Oe/a L, 5: A-LF (> $80 \mu \mathrm{m}), 6$ : Oi.

possible to detect with the experiment the small changes predicted by the model. However, the significant increase in $\Delta{ }^{14} \mathrm{C}$ values observed in the mineral layer two months after the start of the experiment was well outside model predictions (Fig. 8b).

We used the GLUE methodology to explore possible causes of the disagreement between observations and predictions for this particular increase in $\Delta^{14} \mathrm{C}$ values in the mineral fractions two months after the start of the experiment. Evaluating different combinations of the values of the decomposition rates multiplied by a random factor between 0 and 5, we found that none of the parameter combinations produce behavioral models. In other words, increases or decreases of the decomposition rates alone cannot provide model predictions within the range of the observed values in the warming and $\mathrm{N}$ treatments two months after the start of the experiment (Fig. 9).

\subsubsection{Evaluation of Hypothesis 4}

To test the idea that experimental manipulations can result in an increase of the fast-cycling pool at the expense of the intermediately aged pool, we included an additional parameter in the model proposed by Gaudinski et al. (2000). This parameter takes a fraction of the carbon stored in the frac-
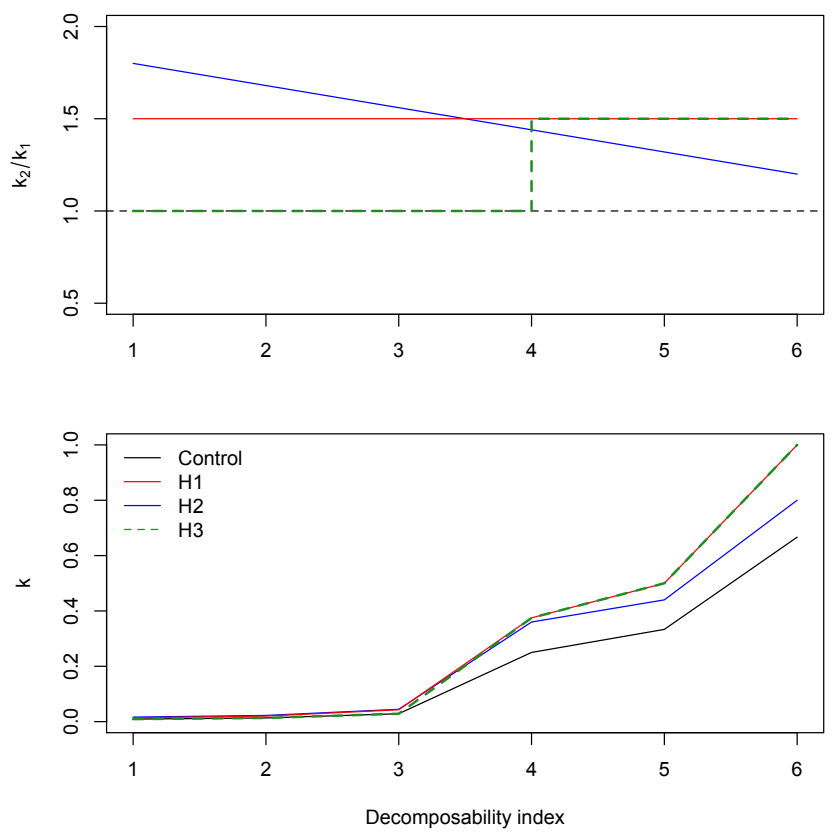

Fig. 7. Hypotheses about changes in decomposition rates due to warming and nitrogen additions. The upper panel shows the three hypotheses represented as a proportional increase in decomposition rates $\left(k_{2} / k_{1}\right.$, where $k_{1}$ is the initial rate and $k_{2}$ is the rate after warming or $\mathrm{N}$ addition). The lower panel represents these hypotheses in absolute values.

tion with a residence time of 75 years and transfers it to the fraction with a 3-yr residence time. The value of this transfer coefficient was set between 0 and 0.1 , and random combinations were draw from this range and evaluated within the GLUE framework.

The results show that the inclusion of this coefficient produces a large number of behavioral models, especially for values above 0.04 (Fig. 10). These simulations suggest that, to explain the observations obtained in the experimental manipulations, we need to modify the model structure to account for a possible transfer of material from the intermediate to the fast-cycling pool.

\section{Discussion}

A combination of radiocarbon measurements in soil $\mathrm{C}$ fractions, soil $\mathrm{CO}_{2}$ efflux both under field and experimental conditions, and a previously developed empirical model provided important insights about the decade-scale nature of carbon cycling in soils at Harvard Forest. The empirical model, which was based on measured $\mathrm{C}$ fractions and the assumption of steady-state, was able to capture the long-term behavior of radiocarbon concentrations and fluxes in the soils of this temperate forest site. This relatively good agreement between observations and model predictions of $\Delta^{14} \mathrm{C}$ values in respired $\mathrm{CO}_{2}$ suggests that empirical estimates of turnover 

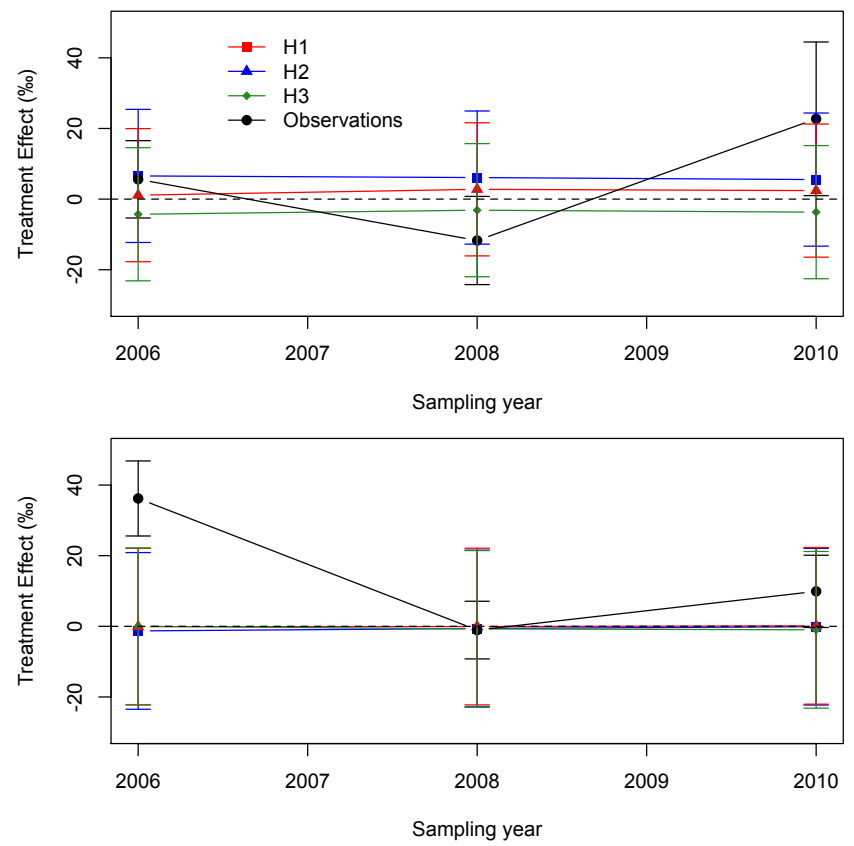

Fig. 8. Observed (in vitro soil incubations) and predicted treatment effects (treatment-control $\Delta^{14} \mathrm{C}$ ) in the warming treatment. The upper panel corresponds to the organic layer (fractions 2, 4, and 6 in Fig. 6) and the lower panel to the mineral layer (fractions 1, 3, and 5 in Fig. 6). Error bars in the observations represent the standard deviation of the sample, and for the model the deviation of predictions with respect to previous observations.

times based on radiocarbon measurements can accurately predict long-term soil carbon dynamics.

Despite possible contributions from subsurface horizons (Braakhekke et al., 2011), the soil ${ }^{14} \mathrm{CO}_{2}$ effluxes reported here can be well explained by a model that only considers the organic and mineral horizons, consistent with previous studies at Harvard Forest that suggest a large contribution from surface horizons to soil respiration (Davidson et al., 2006).

\subsection{Model performance}

Different tests on the empirical steady-state model proposed by Gaudinski et al. (2000) suggest that the degree of complexity already in the model satisfactorily predicts average $\Delta^{14} \mathrm{C}$ values in $\mathrm{CO}_{2}$ fluxes under natural conditions. First, frequent measurements of radiocarbon in soil $\mathrm{CO}_{2}$ efflux suggest that model predictions are robust over decadal timescales. Second, re-measurements in 2007 of radiocarbon concentrations in the bulk soil, 11 years after the original measurements used to constrain the empirical model, suggest that the model is able to predict the general trend of radiocarbon content in different organic matter fractions.

However, the model was less robust at predicting the shortterm, transient effects of ecosystem-scale manipulations on these soils. Particularly, changes in decomposition rates of the different pools were not sufficient to explain the large but short-term release of decade-old carbon observed in the soil warming and nitrogen addition study.

Operationally defined $\mathrm{C}$ fractions, like those presented in this study, can often be misinterpreted and do not necessarily represent biologically meaningful fractions (Crow et al., 2007). In our case, however, density separation of fractions, combined with radiocarbon estimation of mean residence times, provided significant predictive power of decade-scale carbon dynamics, but did not as well at predicting short-term transient responses to manipulation experiments - a point to which we return below.

\subsection{Treatment effects in soil $\mathrm{CO}_{2}$ efflux}

In the experimental manipulation studies, we found a large degree of variability in measured radiocarbon concentrations in respired $\mathrm{CO}_{2}$. This variability was an important limitation to identify the response of carbon fractions that may react more strongly to experimental warming and nitrogen addition.

The variability of $\Delta^{14} \mathrm{C}$ values was larger when measured in the field as total $\mathrm{CO}_{2}$ efflux than when measured in the laboratory as heterotrophic respiration. This variability suggests that root respiration contributed considerably to the observed variation in $\Delta^{14} \mathrm{C}$ values. Estimates of turnover times of fine roots at Harvard Forest can vary between years to decades (Gaudinski et al., 2001, 2010), which partly explain the large variability in the $\Delta^{14} \mathrm{C}$ values of the respired $\mathrm{CO}_{2}$ found here. Other measurements of soil respiration have also shown an important degree of variability in radiocarbon values with important contributions from fine-root dynamics (e.g. Cisneros-Dozal et al., 2007; Jackson et al., 2009).

\subsection{Treatment effects in root-free incubations}

Radiocarbon measurements in the respired $\mathrm{CO}_{2}$ of the incubated soils also showed an important degree of variability, but in this case we were able to detect treatment effects for soils collected from the mineral layer. The organic layer did not show any significant differences in $\Delta^{14} \mathrm{C}$ values compared to the control treatment, which could be the result of two different factors. One factor is that the sizes of the carbon fractions in the organic layer that potentially have larger increases in decomposition rates are very small and contribute only a small proportion to the total $\mathrm{C}$ mass. So, although warming and $\mathrm{N}$ addition may have increased considerably the decomposition rates for these pools, the absolute effect on $\Delta^{14} \mathrm{C}$ values was not large enough to be detected by our method.

Another factor contributing to this lack of treatment effect was more of a technical nature. The cables buried in the soil to warm the plots were inserted below the O-horizon, so they warm the mineral layer more directly and, by heat diffusion, the organic layer. However, it is unlikely that this technical issue had a significant effect on the results. First, the lack 

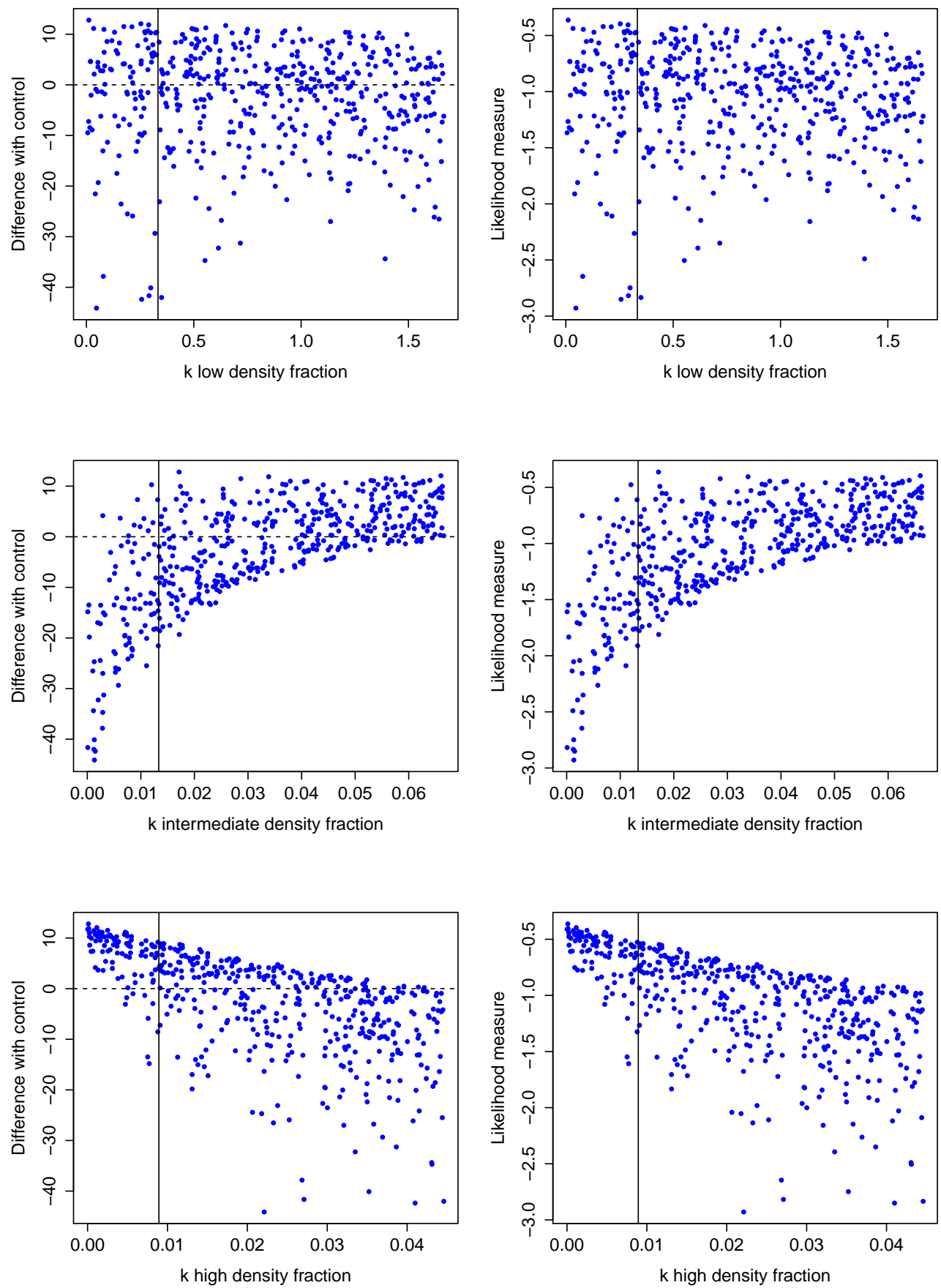

Fig. 9. Dotty plots generated by randomly modifying the values of the decomposition rates of the different fractions by a factor between 0

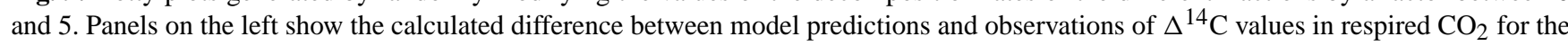
mineral fractions two months after the start of the experimental manipulations. Panels on the right show the value of the likelihood measure, where only positive numbers represent behavioral models; i.e. none of the simulations can be accepted in this case.

of snow accumulation in the warming plots during wintertime suggests that heat is conducted effectively through the O- horizon. This was confirmed by the thermistors that monitor temperatures at each plot and ensure $\mathrm{a}+5^{\circ}$ temperature differential. These thermistors are located in the organic hori- zon at $5 \mathrm{~cm}$ depth. Second, $\mathrm{N}$ additions would have shown a significant effect on the O-horizon because nitrogen was directly applied to this layer. However, we did not find any effect of either warming or $\mathrm{N}$ addition, which is a strong indication that the first possibility described above, a response 

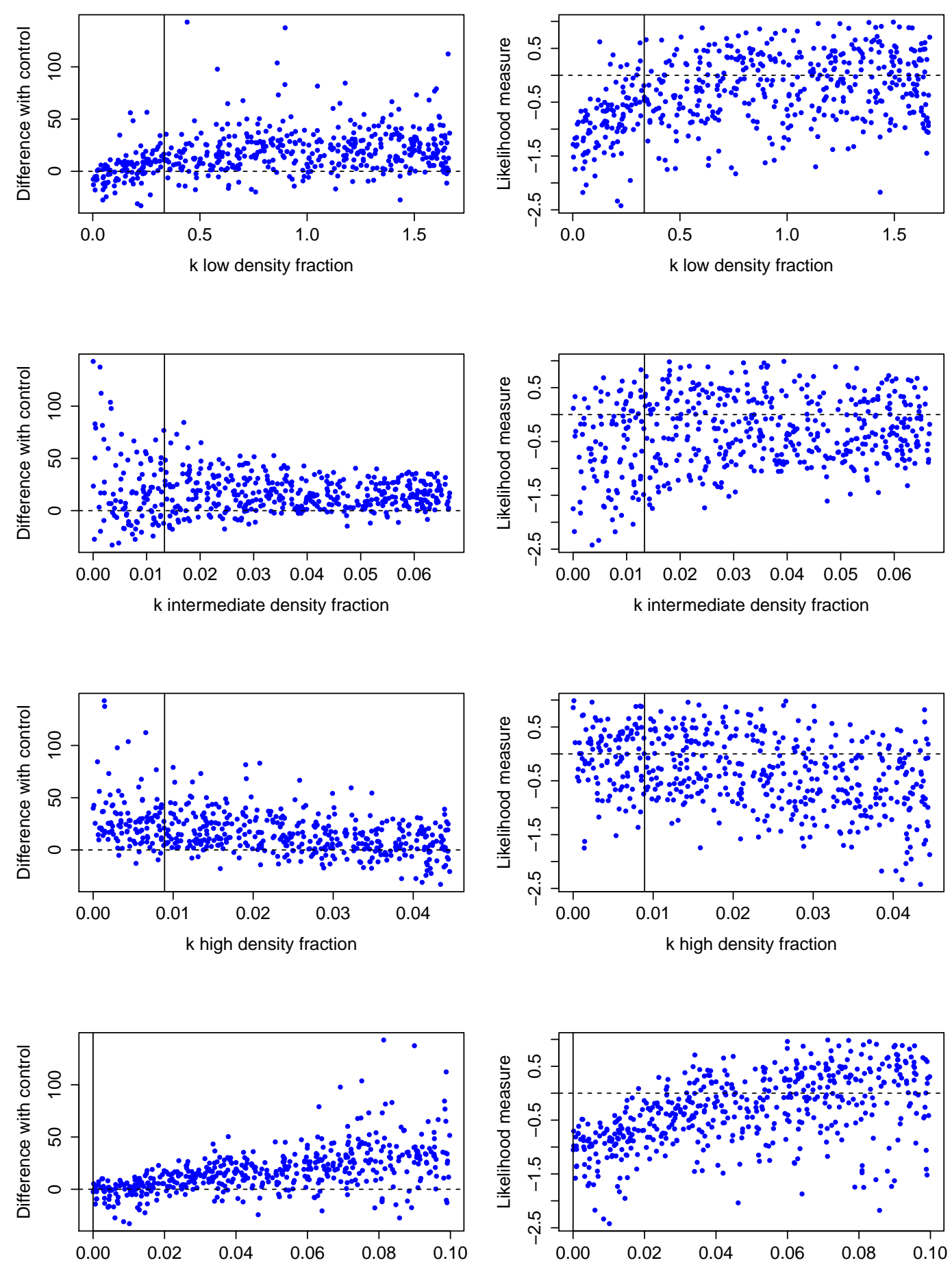

Fraction transferred from intermediate to labile pool

Fraction transferred from intermediate to labile pool

Fig. 10. Dotty plots generated by randomly modifying the values of the decomposition rates and the transfer from the intermediate pool to the labile pool. Panels on the left show the calculated difference between model predictions and observations of $\Delta^{14} \mathrm{C}^{1}$ values in respired $\mathrm{CO}_{2}$ for the mineral fractions two months after the start of the experimental manipulations. Panels on the right show the value of the likelihood measure. Positive values in the likelihood measure represent behavioral models. 
associated with pool sizes, is the most likely explanation for the lack of treatment effects in the organic layer.

In contrast to the observed results for the organic layer, we found treatment effects for the mineral layer. Indeed, we found differences of $\Delta^{14} \mathrm{C}$ values in the treated plots compared to the control, with higher $\Delta^{14} \mathrm{C}$ values that suggest the release of decade-old carbon. Interestingly, the response of the three different treatments two months after the start of the experiment was almost identical (Fig. 5b), which suggests that the mechanisms stimulated by warming and $\mathrm{N}$ additions operated over similar carbon sources.

However, our results suggest that this experimental response in the mineral layer may be transient. The treatment effects were more pronounced two months after the start of the experimental manipulations. Two years after the start of the experiment, these treatment effects disappeared. However, it is puzzling that we found small but significant effects again for the $\mathrm{N}$ addition treatments four years after the start of the experiment. An explanation of this later response is elusive with the available information and could be associated with more complex responses not included in the empirical model.

\subsection{Hypothetical response of $\mathrm{C}$ fractions to warming and $N$ addition}

The response of $\Delta^{14} \mathrm{C}$ values in the Warming $\times$ Nitrogen Addition Study could not be attributed to any of the hypothetical responses related to changes in the value of the decomposition rate $(\mathrm{H} 1, \mathrm{H} 2$, and $\mathrm{H} 3)$. In these three cases, the treatment effects predicted by the hypotheses were very small compared to the degree of variability observed in the experimental data. However, we feel confident about rejecting Hypothesis 3 (H3 - i.e., that only the labile fraction is temperature sensitive), because an increase in the decomposition rates of only the fast-cycling fractions would have caused a small decline in $\Delta^{14} \mathrm{C}$ values compared to the control treatment. The experimental data, however, suggest an increase rather than a decrease in $\Delta{ }^{14} \mathrm{C}$ values with respect to the control treatment. The constant response of all pools predicted by Hypothesis 1 does predict a small increase in $\Delta^{14} \mathrm{C}$ values in the mineral layer, but this predicted effect is very small and with little relevance for hypothesis testing.

Our simulations suggest that the transient increase in $\Delta^{14} \mathrm{C}$ values observed at two months following initiation of the warming treatment could only be the result of a strong response of the intermediate fraction, because a strong response in either the fast or slow cycling fractions would have caused a decrease in $\Delta^{14} \mathrm{C}$ values compared to the control treatment. Furthermore, increases in the decomposition rate of this pool up to five times the control value are not sufficient to increase $\Delta^{14} \mathrm{C}$ values comparable to the observed ones (Fig. 9).

More than a change in the value of the decomposition rates of the intermediate fraction, the observed changes in $\Delta^{14} \mathrm{C}$ can potentially be explained by a change in the size of the fast and intermediate fractions. Although this idea lacks a strong mechanistic support, it has been frequently suggested to explain possible consequences of experimental warming (MacDonald et al., 1995; Zoog et al., 1997; Waldrop and Firestone, 2004; Hopkins et al., 2012). This transfer of material between pools was not included in the original model proposed by Gaudinski et al. (2000); however, our results suggest that the present model structure lacks a process to account for the observed results.

At this point, we can only speculate about possible mechanisms involved in this short-term response of $\Delta^{14} \mathrm{C}$ values to experimental warming and $\mathrm{N}$ additions in the mineral layer. First, it is possible that the humified fraction in the A-horizon (A-LF $>80 \mu \mathrm{m}$ ) is actually a mix of several sub-pools with different decomposition rates. In this case, a strong response of a portion of this fraction could be responsible for the observed $\Delta^{14} \mathrm{C}$ values, and a more complex model with additional pools might be needed. Second, it is possible that the experimental manipulations made some fractions more accessible to enzymatic decomposition by stimulating the quantity and/or types of enzymes produced or by breaking down stabilization mechanisms, such as stimulating desorption from mineral surfaces or increasing turnover of soil aggregates. In this second explanation, some soil C substrates would be effectively "switching pools" in the model, from one with a low decomposition rate to one with a higher rate. It is important to remember that the pools in the present empirical model are defined by measured mean radiocarbon age, and not by any particular process of stabilization. This approach worked well for predicting decadal-scale changes in $\Delta^{14} \mathrm{C}$ values on soils not being experimentally manipulated, but a different model structure that addresses stabilization/destabilization processes (Schmidt et al., 2011; Sierra et al., 2011) might be needed to explain the transient responses observed in the present experiments.

\section{Summary and conclusions}

The re-measurement of soil-C fractions in 2007, 11 years after the initial measurements used to constrain the empirical model, and frequent measurements of $\Delta^{14} \mathrm{C}$ efflux over the intervening decade demonstrated that the empirical model of Gaudinski et al. (2000) provides a good estimation of six measurable soil $\mathrm{C}$ fractions and their mean residence times, and that this relatively simple model is useful for understanding the contributions of these pools to total soil $\mathrm{CO}_{2}$ efflux under field conditions. However, when challenged with data from a temperature manipulation and nitrogen addition experiment, the model was able to simulate most but not all of the observations. This result suggests that the model structure may be inadequate to account fully for the processes that responded to these manipulations in the short term, but can 
account for long-term dynamics currently occurring in these soils under steady-state conditions.

Radiocarbon measurements in the warming and nitrogen addition experiment provided some insights about the contribution of different soil $\mathrm{C}$ fractions in the mineral layer to total $\mathrm{CO}_{2}$ efflux. Two months after the start of the experiment, the $\mathrm{CO}_{2}$ released from the warming and $\mathrm{N}$ addition treatments was significantly enriched with decade-old carbon. With the aid of the empirical model, we can rule out that this shortterm release of old carbon was caused by an increase in the decomposition rates of the fast-cycling fractions only. It is possible that all rates increased by the same proportion such as with a constant $\mathrm{Q}_{10}$ value, or in a higher proportion for the slow- than for the fast-cycling fractions, but these two hypotheses could not be rejected or fully supported in our analysis. It is also possible that the observed short-term increase in $\Delta^{14} \mathrm{C}$ values is related to complex mechanisms related to changes in microbial community composition, enzyme activity, or organic matter desorption from mineral surfaces, among others. These other mechanisms, however, are not included in our model and pose a challenge for predicting short-term effects of environmental change on the cycling of organic matter in different soil fractions.

\section{Supplementary material related to this article is available online at: http://www.biogeosciences.net/9/ 3013/2012/bg-9-3013-2012-supplement..zip.}

\begin{abstract}
Acknowledgements. Financial support was provided by the Northeastern Regional Center of the National Institute for Climatic Change Research, Grant No. DE-FC02-06ER64157, and the Max Planck Society. We thank Werner Borken and Julia Gaudinski for field data collection, Matthew Khosh for 2007 density separations, and Xiaomei $\mathrm{Xu}$ and the WM Keck Carbon Cycle AMS at UC Irvine for measurements of radiocarbon.
\end{abstract}

Edited by: J. Leifeld

The service charges for this open access publication have been covered by the Max Planck Society.

\section{References}

Beven, K.: A manifesto for the equifinality thesis, J. Hydrol., 320, 18-36, doi:10.1016/j.jhydrol.2005.07.007, 2006.

Beven, K. and Binley, A.: The future of distributed models: Model calibration and uncertainty prediction, Hydrol. Process., 6, 278298, doi:10.1002/hyp.3360060305, 1992.

Bond-Lamberty, B. and Thomson, A.: Temperature-associated increases in the global soil respiration record, Nature, 464, 579582, doi:10.1038/nature08930, 2010.

Borken, W., Savage, K., Davidson, E. A., and Trumbore, S. E.: Effects of experimental drought on soil respiration and radiocarbon efflux from a temperate forest soil, Global Change Biol., 12, 177-193, doi:10.1111/j.1365-2486.2005.001058.x, 2006.

Bowden, R. D., Davidson, E., Savage, K., Arabia, C., and Steudler, P.: Chronic nitrogen additions reduce total soil respiration and microbial respiration in temperate forest soils at the Harvard Forest, Forest Ecol. Manag., 196, 43-56, 2004.

Braakhekke, M. C., Beer, C., Hoosbeek, M. R., Reichstein, M., Kruijt, B., Schrumpf, M., and Kabat, P.: SOMPROF: a vertically explicit soil organic matter model, Ecol. Model., 222, 17121730, 2011.

Canham, C. D., Cole, J. J., and Lauenroth, W. K.: Models in Ecosystem Science, in: Models in ecosystem science, edited by: Canham, C. D., Cole, J. J., and Lauenroth, W. K., Princeton University Press, Princeton, 1-10, 2003.

Cisneros-Dozal, L. M., Trumbore, S. E., and Hanson, P. J.: Effect of moisture on leaf litter decomposition and its contribution to soil respiration in a temperate forest, J. Geophys. Res., 112, G01013, doi:10.1029/2006jg000197, 2007.

Conant, R. T., Ryan, M. G., Ågren, G. I., Birge, H. E., Davidson, E. A., Eliasson, P. E., Evans, S. E., Frey, S. D., Giardina, C. P., Hopkins, F. M., Hyvönen, R., Kirschbaum, M. U. F., Lavallee, J. M., Leifeld, J., Parton, W. J., Steinweg, J. M., Wallenstein, M. D., Wetterstedt, J. A. M., and Bradford, M. A.: Temperature and soil organic matter decomposition rates synthesis of current knowledge and a way forward, Glob. Change Biol., 17, 33923404, doi:10.1111/j.1365-2486.2011.02496.x, 2011.

Contosta, A. R., Frey, S. D., and Cooper, A. B.: Seasonal dynamics of soil respiration and $\mathrm{N}$ mineralization in chronically warmed and fertilized soils, Ecosphere, 2, art36, doi:10.1890/ES1000133.1, 2011.

Crow, S., Swanston, C., Lajtha, K., Brooks, J., and Keirstead, H.: Density fractionation of forest soils: methodological questions and interpretation of incubation results and turnover time in an ecosystem context, Biogeochemistry, 85, 69-90, doi:10.1007/s10533-007-9100-8, 2007.

Davidson, E. A. and Janssens, I. A.: Temperature sensitivity of soil carbon decomposition and feedbacks to climate change, Nature, 440, 165-173, 2006.

Davidson, E. A., Belk, E., and Boone, R. D.: Soil water content and temperature as independent or confounded factors controlling soil respiration in a temperate mixed hardwood forest, Global Change Biol., 4, 217-227, doi:10.1046/j.13652486.1998.00128.x, 1998.

Davidson, E. A., Savage, K. E., Trumbore, S. E., and Borken, W.: Vertical partitioning of $\mathrm{CO}_{2}$ production within a temperate forest soil, Global Change Biol., 12, 944-956, http://dx.doi. org/10.1111/j.1365-2486.2005.01142.xdoi:10.1111/j.13652486.2005.01142.x, 2006. 
Fang, C., Smith, P., Moncrieff, J. B., and Smith, J. U.: Similar response of labile and resistant soil organic matter pools to changes in temperature, Nature, 433, 57-59, doi:10.1038/nature03138, 2005.

Fisher, R. T.: An account of operations in the Harvard Forest, 190809, Harvard Forest Bull., 1, 1-9, 1921.

Foster, D. R.: Species and stand response to catastrophic wind in Central New England, USA, J. Ecol., 76, 135-151, 1988.

Frey, S. D., Knorr, M., Parrent, J. L., and Simpson, R. T.: Chronic nitrogen enrichment affects the structure and function of the soil microbial community in temperate hardwood and pine forests, Forest Ecol. Manag., 196, 159-171, 2004.

Gaudinski, J. B., Trumbore, S. E., Davidson, E. A., and Zheng, S.: Soil carbon cycling in a temperate forest: radiocarbon-based estimates of residence times, sequestration rates and partitioning fluxes, Biogeochemestry, 51, 33-69, 2000.

Gaudinski, J., Trumbore, S. E., Davidson, E. A., Cook, A., Markewitz, D., and Richter, D.: The age of fine-root carbon in three forests of the Eastern United States measured by radiocarbon, Oecologia, 129, 420-429, doi:10.1007/s004420100746, 2001.

Gaudinski, J. B., Torn, M. S., Riley, W. J., Swanston, C., Trumbore, S. E., Joslin, J. D., Majdi, H., Dawson, T. E., and Hanson, P. J.: Use of stored carbon reserves in growth of temperate tree roots and leaf buds: analyses using radiocarbon measurements and modeling, Glob. Change Biol., 15, 992-1014, doi:10.1111/j.1365-2486.2008.01736.x, 2009.

Gaudinski, J. B., Torn, M. S., Riley, W. J., Dawson, T. E., Joslin, J. D., and Majdi, H.: Measuring and modeling the spectrum of fine-root turnover times in three forests using isotopes, minirhizotrons, and the Radix model, Global Biogeochem. Cy., 24, GB3029, doi:10.1029/2009gb003649, 2010.

Hopkins, F. M., Torn, M. S., and Trumbore, S. E.: Warming accelerates decomposition of decades-old carbon in forest soils, Proc. Natl. Acad. Sci., doi:10.1073/pnas.1120603109, 2012.

Jackson, R. B., Cook, C. W., Pippen, J. S., and Palmer, S. M.: Increased belowground biomass and soil $\mathrm{CO}_{2}$ fluxes after a decade of carbon dioxide enrichment in a warm-temperate forest, Ecology, 90, 3352-3366, doi:10.1890/08-1609.1, 2009.

Janssens, I. A., Dieleman, W., Luyssaert, S., Subke, J. A., Reichstein, M., Ceulemans, R., Ciais, P., Dolman, A. J., Grace, J., Matteucci, G., Papale, D., Piao, S. L., Schulze, E. D., Tang, J., and Law, B. E.: Reduction of forest soil respiration in response to nitrogen deposition, Nat. Geosci., 3, 315-322, doi:10.1038/ngeo844, 2010.

Levin, I. and Kromer, B.: The tropospheric ${ }^{14} \mathrm{CO}_{2}$ level in midlatitudes of the Northern Hemisphere (1959-2003), Radiocarbon, 46, 1261-1272, 2004.

Lloyd, J. and Taylor, J. A.: On the temperature dependence of soil respiration, Funct. Ecol., 8, 315-323, 1994.

MacDonald, N. W., Zak, D. R., and Pregitzer, K. S.: Temperature effects on kinetics of microbial respiration and net nitrogen and sulfur mineralization, Soil Sci. Soc. Am. J., 59, 233-240, doi:10.2136/sssaj1995.03615995005900010036x, 1995.

Melillo, J. M., Steudler, P. A., Aber, J. D., Newkirk, K., Lux, H., Bowles, F. P., Catricala, C., Magill, A., Ahrens, T., and Morrisseau, S.: Soil warming and carbon-cycle feedbacks to the climate system, Science, 298, 2173-2176, doi:10.1126/science.1074153, 2002.
Melillo, J. M., Butler, S., Johnson, J., Mohan, J., Steudler, P., Lux, H., Burrows, E., Bowles, F., Smith, R., Scott, L., Vario, C., Hill, T., Burton, A., Zhou, Y.-M., and Tang, J.: Soil warming, carbon, and nitrogen interactions, and forest carbon budgets, P. Natl. Acad. Sci. USA, 108, 9508-9512, doi:10.1073/pnas.1018189108, 2011.

Mesirov, J. P.: Accessible reproducible research, Science, 327, 415416, doi:10.1126/science.1179653, 2010.

Nowinski, N., Taneva, L., Trumbore, S., and Welker, J.: Decomposition of old organic matter as a result of deeper active layers in a snow depth manipulation experiment, Oecologia, 163, 785792, doi:10.1007/s00442-009-1556-x, 2010.

Peng, R. D.: Reproducible research in computational science, Science, 334, 1226-1227, doi:10.1126/science.1213847, 2011.

Reichstein, M., Subke, J. A., Angeli, A. C., and Tenhunen, J. D.: Does the temperature sensitivity of decomposition of soil organic matter depend upon water content, soil horizon, or incubation time?, Global Change Biol., 11, 1754-1767, doi:10.1111/j.13652486.2005.001010.x, 2005.

Rustad, L., Campbell, J., Marion, G., Norby, R., Mitchell, M., Hartley, A., Cornelissen, J., Gurevitch, J., and GCTENEWS: A meta-analysis of the response of soil respiration, net nitrogen mineralization, and aboveground plant growth to experimental ecosystem warming, Oecologia, 126, 543-562, doi:10.1007/s004420000544, 2001.

Savage, K. E. and Davidson, E. A.: Interannual variation of soil respiration in two New England forests, Global Biogeochem. Cy., 15, 337-350, doi:10.1029/1999gb001248, 2001.

Schlesinger, W. H. and Andrews, J. A.: Soil respiration and the global carbon cycle, Biogeochemistry, 48, 7-20, doi:10.1023/a:1006247623877, 2000.

Schmidt, M. W. I., Torn, M. S., Abiven, S., Dittmar, T., Guggenberger, G., Janssens, I. A., Kleber, M., Kogel-Knabner, I., Lehmann, J., Manning, D. A. C., Nannipieri, P., Rasse, D. P., Weiner, S., and Trumbore, S. E.: Persistence of soil organic matter as an ecosystem property, Nature, 478, 49-56, 2011.

Sierra, C.: Temperature sensitivity of organic matter decomposition in the Arrhenius equation: some theoretical considerations, Biogeochemistry, 108, 1-15, doi:10.1007/s10533-011-9596-9, 2012.

Sierra, C. A., Harmon, M. E., and Perakis, S. S.: Decomposition of heterogeneous organic matter and its long-term stabilization in soils, Ecol. Monogr., 81, 619-634, doi:10.1890/11-0811.1, 2011.

Stuiver, M. and Polach, H. A.: Reporting of C-14 data-discussion, Radiocarbon, 19, 355-363, 1977.

Treseder, K. K.: Nitrogen additions and microbial biomass: a metaanalysis of ecosystem studies, Ecol. Lett., 11, 1111-1120, doi:10.1111/j.1461-0248.2008.01230.x, 2008.

Trumbore, S.: Age of soil organic matter and soil respiration: radiocarbon constraints on belowground $\mathrm{C}$ dynamics, Ecol. Appl., 10, 399-411, doi:10.1890/10510761(2000)010[0399:AOSOMA]2.0.CO;2, 2000.

Trumbore, S.: Radiocarbon and soil carbon dynamics, Annu. Rev. Earth Pl. Sc., 37, 47-66, doi:10.1146/annurev.earth.36.031207.124300, 2009.

Trumbore, S. E., Davidson, E. A., Barbosa de Camargo, P., Nepstad, D. C., and Martinelli, L. A.: Belowground cycling of carbon in forests and pastures of Eastern Amazonia, Global Biogeochem. Cy., 9, 515-528, doi:10.1029/95gb02148, 1995. 
Waldrop, M. P. and Firestone, M. K.: Altered utilization patterns of young and old soil $\mathrm{C}$ by microorganisms caused by temperature shifts and $\mathrm{N}$ additions, Biogeochemistry, 67, 235-248, doi:10.1023/b:biog.0000015321.51462.41, 2004.

Wetterstedt, J. Å. M. and Ågren, G. I.: Quality or decomposer efficiency - which is most important in the temperature response of litter decomposition? A modelling study using the GLUE methodology, Biogeosciences, 8, 477-487, doi:10.5194/bg-8477-2011, 2011.
Xu, X., Trumbore, S. E., Zheng, S., Southon, J. R., McDuffee, K. E., Luttgen, M., and Liu, J. C.: Modifying a sealed tube zinc reduction method for preparation of AMS graphite targets: reducing background and attaining high precision, Nucl. Instrum. Meth. B, 259, 320-329, 2007.

Zogg, G. P., Zak, D. R., Ringelberg, D. B., White, D. C., MacDonald, N. W., and Pregitzer, K. S.: Compositional and functional shifts in microbial communities due to soil warming, Soil Sci. Soc. Am. J., 61, 475-481, doi:10.2136/sssaj1997.03615995006100020015x, 1997. 